\title{
A discourse analysis of managerialism and trust amongst nursing professionals
}

Research Article

\author{
Thomas Joseph McCabe ${ }^{1 *}$, Sally Anne Sambrook ${ }^{2}$ \\ 'National College of Ireland, Dublin, Ireland \\ ${ }^{2}$ Bangor, University, Wales, UK
}

\begin{abstract}
This study explores the effects of New Public Management (NPM) on trust amongst nursing professionals, nurses and nurse ward managers within the British National Health Service (NHS). Thirty-nine nurses and nurse ward managers, recruited randomly, participated in semi-structured interviews. The original data, collected in 2000-2002, are re-analysed from a discourse analysis perspective. The findings support and extend contemporary research. They show that nurses have a strong professional identity and commitment and that increasing managerialism is eroding trust. Nurses both accommodate and resist managerialist discourses. They conceptualise trust in terms of their own ward environment, line-manager and colleagues. Trust is reciprocal and related to previous experiences and other factors. Trust is beneficial to healthcare organisations, healthcare professionals and their patients. Good communication and openness positively influence the development of trust. Nurse ward managers play a pivotal role in translating contested managerialist discourse into nursing practice to sustain trust and effect professional patient care.
\end{abstract}

Keywords: over 50s; labour market; economically active

(C) Sciendo

\section{INTRODUCTION}

As health organisations across the globe face intense pressures, 'managerialism' and New Public Management (NPM) have replaced traditional healthcare management practices. In this study, our overall research question is: What are the effects of 'managerialism' and NPM on trust amongst nursing professionals in two British National Health Service (NHS) organisations? We explore this through a discourse analysis of interviews with 39 nurse professionals at various stages in their nurse and nurse managerial, 'hybrid', careers.

We focus on trust, which considered an important leader characteristic. Research suggests that nurse managers play a significant role in positively and negatively influencing trust within health service organisations (Calnan and Rowe, 2006; Tallman, 2007). Laschinger and Finegan (2005) found that organisational 'restructuring' in Canadian health service organisations led to decreasing levels of trust between nurses and managers. Low levels of trust can result in declining levels of morale and commitment, and increased levels of work-related stress amongst nursing professionals, resulting in poor organisational performance (Williams, 2005). Strategies aimed at increasing and retaining existing nursing staff and good nursing practice require work environments built on trust, respect and justice (Laschinger and Finegan, 2005).

The paper re-analyses, from a discourse perspective, interview material involving 39 nurses and nurse managers - collected in 2000-2002. We argue that the paper is timely, offering new perspectives still relevant in the current healthcare context. Our findings both support and extend contemporary research, demonstrating that nurses accommodate and resist managerialist discourses. Nurses have a strong professional identity and commitment yet increasing managerialism is eroding trust. Trust is beneficial to healthcare organisations, healthcare professionals and their patients. Good communication and openness positively influence the development of trust. Nurse ward managers play a pivotal role in translating contested managerialist discourse into nursing practice to sustain trust and effect professional patient care. We make two contributions to the literature on managerialism and trust in the healthcare context and consider implications for healthcare management. 
First we introduce the context and review the literature pertaining to NPM, managerial and professional nursing discourses, hybrid roles, and trust. Next, we outline the methodology before presenting our findings. After our discussion, we conclude and consider implications for nursing management.

\section{BACKGROUND AND CONTEXT}

\section{New public management}

During the 1990s, due to increasing conflicts with state and service users, healthcare organisations worldwide underwent public policy reform (Gilbert, 2005). Health service organisations adopted strategies involving privatisation, marketization and performance management (Hassard, et al., 2017). The changes within UK health care had dramatic consequences for the management of health care (Bresnen, et al., 2017; Hyde et al., 2016). Many organisations 'downsized' to achieve cost containment (Cope, et al., 2016). 'Managerialist' systems and structures, labelled 'New Public Management', were introduced to more effectively govern the public sector (Calnan and Gabe 2001; O'Reilly and Reed, 2010). These reforms took place within the context of financial crises, increasing healthcare demands, and an ageing nurse workforce (Hassard, et al., 2017; Buchan et al., 2013), with retention problems and skill shortages amongst existing nursing professionals (Jefferson et al., 2014).

A prime objective of NPM in the NHS involved the recruitment of professional managers (Hoyle, 2014), with a managerial but not necessarily a healthcare background (Hunter 2007; Townsend and Wilkinson, 2010; Yu and Levy 2010). However, many healthcare professionals expressed concerns that the new managers were more committed to general business management values such as entrepreneurship, innovation, competency, efficiency and financial management (De Vries and Nemec, 2013), with insufficient understanding of, and consideration for, patient care.

While NHS 'managers' had previously struggled with medical staff for power and legitimacy, 'managerialism' then became the dominant policy discourse of public service modernisation (Reed and O'Reilly, 2011). Over the last 10-15 years, the dominant discourse within the NHS moved away from 'administration' and 'management' to 'leadership' or 'leaderism' (Learmonth, 2017; Martin and Learmonth, 2012). The role of leader, rather than manager, was considered more legitimate and acceptable from a public perspective (Learmonth, 2017), and was used to build support and overcome professional resistance to general management responsibilities.

Over the same period, there has been a steady increase in work intensity and demands across the public sector (Granter et al., 2018). While certain aspects of health professionals' work can be intrinsically intense, 'organisational elements' can make work intensity potentially hazardous. Work intensity is generally considered as workload versus time, involving a fast pace of work and long working hours (Felstead et al., 2013). This has contributed to labour turnover and declining numbers entering the nursing profession (Newman et al., 2002; Skinner, et al., 2004), now considered by many as a 'stressful' profession (Scudder, et al., 2011). Also, in trying to be viewed as effective "nurse managers", many nurses abandoned their profession (Traynor 1999). With increasing managerialism, the profession has become 'unrecognisable as something nurses or patients wish to engage with' (Carter, 2007: 270).

\section{Managerialism and managerial discourses}

Managerialism is defined as:

the belief that all aspects of organizational life can and should be managed according to rational structures, procedures, and modes of accountability in the pursuit of goals defined by policymakers and senior managers. (Wallace and Pocklington 2002:68)

Gilbert (2005) suggests that 'managerialism' represents a clearly defined set of concepts, practices and discourses. Associated discourses such as 'performance management', 'flexibility', 'quality' and 'customer service' have initiated debates about the nature of nursing and healthcare provision (Gilbert, 2005; Nordgren, 2008).

Academic nursing discourse is conceptually fluid and open to other discourses, in particular managerial discourses (McNamara, 2009). The vocational focus traditionally associated with the nursing profession has now been informed by emerging academic nursing theories that have largely abandoned 'front-line illness care' and 'bedside nursing work' (Clarke 2006:177). Allen (2004:271) proposed an empirical reformulation of the nursing mandate to that of 'healthcare mediator', where the traditional concepts of individual nurse-patient contact linked to holistic care have been substituted with managerial and medical discourses (Latimer, 2000). Tensions amongst 
managers, professionals and service users have been observed on three levels: communication, discourses and values (Gilbert, 2005). Traditional notions of professional autonomy (Reed, 2002), self-regulation (MacDonald, 1995) and judgements around professional standards have been replaced with values such as transparency, accountability (Reinders, 2008) and performance management with controls on outputs and results (Tummers et al., 2009). Reinders (2008) suggests that increasing involvement of professionals with management responsibilities, combined with managers' desire for a strong chain of command and the professional autonomy of clinicians, has contributed to 'low trust' and tensions between clinical staff and healthcare managers (Brown et al., 2011).

Previously, nursing was regulated by professional associations (Hoyle, 2014), where nurses experienced a high degree of autonomy, with strong focus on patient welfare over economic considerations (Freidson, 2001). Changes in state and institutional attitudes towards professional groups led to a decline in professional autonomy (Reed, 2002) and self-regulation (MacDonald, 1995). Traynor (1999) notes how 'managerialist' rhetoric positioned itself in opposition to professional discourses, by putting systems of 'managerial governance' as a counterweight and check on 'professional expertise'. Within professional organisations, managerial leadership is defined as transactional, concerned with day-to-day performance management, efficiency and achieving targets (Currie and Lockett, 2007). Despite the apparent dominance of managerial discourse, there is evidence of continuing dependence on the knowledge and professional expertise of healthcare professionals (Gilbert, 2005). Some researchers comment on the capacity of professional groups to resist 'managerialism', essentially by adopting strategies that allow them to maintain or increase their influence within their respective institutions (Carvalho, 2012).

\section{Professional hybrids}

In undertaking managerial roles, whilst at the same time retaining influence and leadership of their respective professional groups (Croft et al., 2015a; Marinetto 2011; Tummers et al., 2012), NPM converted 'doctors' and 'nurses' into managers (professional hybrids). Professional identity develops during education and training (McCabe and Garavan, 2008) and relates to 'what you do' (Pratt et al., 2006). Nurses who undertake hybrid roles often undergo a period of identity conflict (Ibarra and Barbulescu, 2010). Many nursing professionals adapted by expanding their professional boundaries to incorporate managerial roles and responsibilities (Carvalho, 2012). While some nurses embraced managerial discourses (Hallier and Forbes, 2004; Llewellyn, 2001; Kurunmaki, 2004), 'blending' managerial roles and responsibilities with their professional practice (ledema et al., 2004), others experienced difficulty with the competing professional and managerial demands of hybrid roles (Croft et al., 2015a; Traynor, 1999), in particular the caring side of their role (Blomgren, 2003).

Hybrid managers were seen as increasing managerial control (Bejerot and Hasselbladh 2011; Ferlie et al., 2013; Martin and Learmonth, 2012) and as part of a strategy for overcoming professional resistance to organisational reform (Tummers et al., 2012). Croft et al. (2015a, p. 383) explore the concept of liminality in considering how professional hybrids manage identity conflict in constructing new identities. They conclude that the influence across numerous groups relies on creating an 'a positive liminal space' and suggest that nurse hybrids occupy a 'perverse liminal space'. This can perpetuate identity conflict and prevent identity transition, which ultimately undermines their effectiveness as hybrids. When undertaking hybrid roles, Croft et al. (2015a, p. 381) suggest adopting an 'individual-level approach' in balancing professional and managerial responsibilities. This study seeks to further explore the challenges nursing professionals face when transitioning into hybrid manager roles (whether distant or local), and how this affects trust.

\section{Trust}

Newell and Swan (2000) define trust as comprising three elements: companionship, which is based on judgements, goodwill and friendship; competence, which is the ability to perform tasks and duties; and commitment, where parties fulfil their end of 'the bargain'. Trust plays an important mediating role in the relationship between government, healthcare professionals and health service users (Gilbert 2005). Rydenfält et al. (2012) discuss how trust can be affected by the social and organisational context and note the importance of trust amongst professionals, when focused on a common purpose. Connell and Mannion (2006) discuss the crucial role played by trust in healthcare organisations involving professional multi-agency teams that work and cooperate interdependently across organisational and speciality boundaries (Gilson, 2003; Rowe and Calnan, 2006), within a secure working environment (Peter and Morgan, 2001). Gilson (2006) examines the role of trust in health care, exploring issues of equity, justice, policy and managerial priorities. Areas she identifies for policy and management actions in order to sustain trusting relationships include recruitment, training and institutional development. She also discusses the role of 'distrust' as useful in guarding against the abuse of power.

Having reviewed the literature, the next section details our research methods. 


\section{METHOD}

\section{Research questions}

As health professionals internationally continue to face challenges, with increasing job demands within a resourceconstrained context, the continued relevance of understanding factors influencing trust in key relationships within health service organisations is underlined. Given the importance of trust in an increasingly NPM healthcare context, our aim was to explore how 'managerialism' and 'trust' were talked about amongst nursing professionals in two British healthcare organisations, and to examine how they affect managerial and professional nursing relationships. The study involved analysing qualitative interview data from nurses and nurse ward managers. The original data, collected in 2000-2002, were re-analysed from a discourse analysis perspective. With ongoing changes within the British NHS, and a growing emphasis on policies and practices associated with managerialism, we re-interrogated the original data to address two new research questions:

1. What is the effect of managerialism on professional nursing identity/nurse manager relationships, and to what extent do nursing professionals accommodate or resist managerial identities and discourses?

2. What is the influence of managerialism on trust between management and nurses, and how is this talked about?

Semi-structured interviews were considered the most effective method to capture perceptions of managerialism and trust. To gain their collective interpretations, and since managers have key interpretational roles (Bennis and Nanus, 1985; Smircich and Morgan, 1982), we sought the views of both nurses and nurse managers. This re-analysis of the interview texts focuses on the language and discourses used by nursing professionals, in relation to managerialism and trust and the connection both phenomena have with the professional identities of nurses and nurse managers (Potter and Wetherell, 1987).

Two NHS organisations were selected: an acute hospital and a community hospital. The participants were informed about the study through their line-manager and selected through a process of random sampling $(n=39)$. The sample reflected a variety of age, grade, ward and tenure/length of service - time working within the NHS. They included nurse ward managers and nurses at various stages of their career, with tenure ranging from 3 to 34 years. Twenty-eight nurses and 11 ward nurse ward managers were interviewed, with 20 from the acute hospital and 19 from the community hospital. The first author briefly explained the purpose of the study and participants consented on a voluntary basis, with confidentiality assured. Sample details are provided in Table 1 below.

Table 1. Participant demographics

\begin{tabular}{|c|c|c|c|c|c|c|c|}
\hline $\begin{array}{l}\text { Years of } \\
\text { service }\end{array}$ & $<5$ & $5-10$ & 11-15 & $16-20$ & 21-25 & 26-30 & $31+$ \\
\hline Acute & & & & & & & \\
\hline Eye Infirmary & & ANM1-F26 & & & AN2-F42 & AN1-F48 & \\
\hline Child Health & & & & & AN3-F45 & & \\
\hline Cardiac & & ANM2-F33 & AN4-F38 & & & & \\
\hline Midwife & AN5-F46 & AN6-F26 & & ANM3-F54 & & & \\
\hline Neurology & & & AN7-F30 & & & & \\
\hline Haematology & & AN8-F25 & AN9-F34 & ANM4-F39 & & & \\
\hline Anaesthetics & & & ANM6-M37 & & & & \\
\hline Renal & & & ANM8-F36 & & & AN10-E47 & \\
\hline Orthopaedic & & & & & & AN12-F43 & \\
\hline Oncology & & & ANM5-F35 & & & & \\
\hline Surgical & & & ANM7-F38 & & & & \\
\hline Community & CN1-F48 & $\begin{array}{l}\text { CN9-F27 } \\
\text { CN10-F32 } \\
\text { CN13-F27 } \\
\text { CNM1-F29 }\end{array}$ & $\begin{array}{l}\text { CN5-F41 } \\
\text { CN6-F33 } \\
\text { CN11-F31 } \\
\text { CN14-F35 }\end{array}$ & CN16-F42 & $\begin{array}{l}\text { CN2-F42 } \\
\text { CN3-F39 } \\
\text { CN4-F40 } \\
\text { CN15-F54 } \\
\text { CNM3-M50 }\end{array}$ & $\begin{array}{l}\text { CN7-F48 } \\
\text { CN8-F48 } \\
\text { CN12-F57 }\end{array}$ & CNM2-F51 \\
\hline
\end{tabular}


The interview schedule, informed by a review of literature, contained open-ended questions regarding managerialism and trust, and was piloted amongst four nurses. While each interview contained the same broad topics, we maintained flexibility to explore areas of significance to participants. The interviews, conducted at participants' workplace facilities, lasted approximately 45 minutes to one hour. They were recorded through note taking and audio cassette and transcribed in full text format. Access to participants was negotiated and approved by $H R$, who acted as the initial point of contact between the interviewer (first author) and interviewees. Approval was granted through the ethics committees of both organisations.

\section{Discourse analysis}

A critical discourse approach can be useful in exploring power relations between nursing professionals and managers. Social phenomena, such as trust and managerialism, are created through language, symbols and words, of which discourses are a part (Sambrook, 2000; Stewart and Sambrook, 2007). The interviews explored professional nursing and management discourses around managerialism and trust, and how these phenomena affect the practice of nursing. The context in which discourses occur is central (Crowe, 2005). Discourse analysis focuses on both the macro and micro levels of discourse use (Fairclough and Wodak, 1997).

The original data were collected between 2000 and 2002, when NPM and managerial discourses were nascent in the NHS. Participants took the lead in discussing management, trust and nursing identity. Given increasing managerialism and its impact on trust in the NHS, we sought to examine, retrospectively, how this was talked about then. Thus, we have re-analysed the data from a discourse analysis perspective. Our analysis reveals that nurses and nurse ward managers were already both recognising and resisting emerging managerialist practices and associated discourses. The themes that emerged from our re-analysis of the qualitative data were based on frequency and the extent to which they were discussed and explored by the participants.

Many commentators have criticised approaches to discourse analysis for lacking sufficient rigour (Kvale, 1996). To address this, careful attention was paid to the transcription/analysis of the interview tapes and discussion of emerging themes. The interview transcripts were analysed line by line, using an inductive theory-building approach, where emerging themes were developed from rigorous analysis of the qualitative interview data. We compared the responses of participants in both organisations, as well as those of nurses and nurse managers, noting any particular discursive resources (Sambrook 2001). Our re-analysis and emerging themes are supported by and extend contemporary research findings. We argue that this research remains timely, offering new perspectives that are still relevant in the current healthcare context.

\section{FINDINGS}

The findings that follow summarise the main themes emerging from our discourse analysis of the 39 in-depth interviews with nurses and nurse ward managers. The first theme and contribution highlight tensions between professional and managerial identities, indicating a strong professional identity amongst the respondents that often conflicts with managerial identities and discourses. These are summarised in Table 2 below. The second theme and contribution reveal conflicting levels of trust, showing high trust amongst line managers and colleagues at ward level (local) versus mistrust of 'distant' senior management (generally viewed as non-nursing). (Figures 1 and 2).

\section{Professional nurse and managerialist identities}

Here, we address our first research question. We summarise our findings on the effect of managerialism on professional nurse identity, nurse manager relationships, and the extent to which nursing professionals accommodated or resisted managerial identities and discourses.

Professional identity, involving a commitment to professional nursing values, emerged as the most dominant theme throughout the discourse analysis. This was articulated in terms of professional pride and autonomy, identity, direct patient contact, holistic care and good nursing practice:

We are all proud to be who we are. It has taken us a long time to get there. We have earned our badges. (Female, age 25, 6 years in NHS, Staff Nurse/Midwife, Maternity, Acute) 
Table 2. Professional and managerial values, and trust amongst nursing professionals

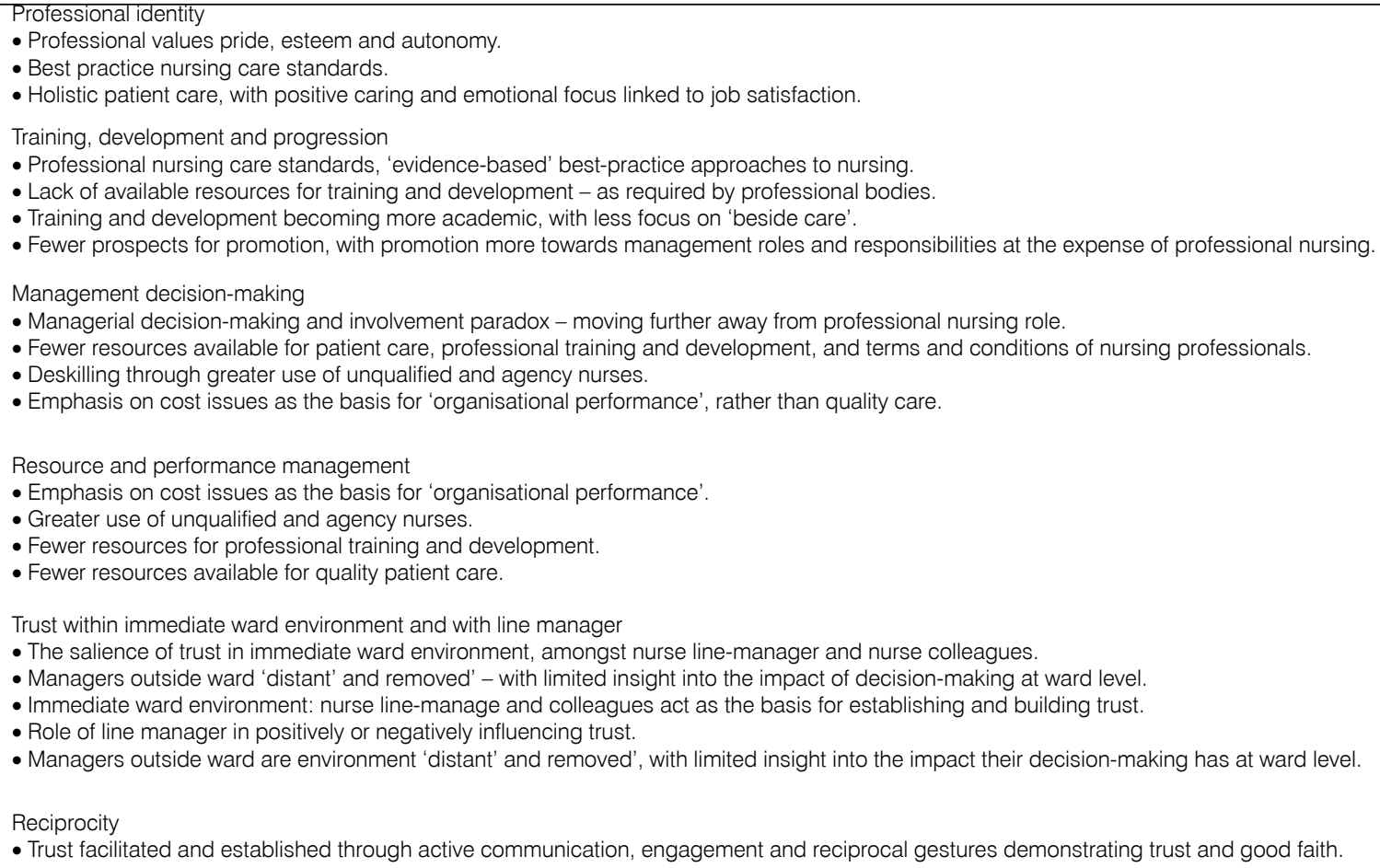

Propensity towards trusting others

- Propensity to trust and reciprocity linked to previous work history, work experience, training, political views, psychological contract issues, profession, staff association and union membership.

The participants talked about belonging to a 'humanistic', 'people-orientated' profession with a strong interest in patient care and welfare. These features were considered key sources of job satisfaction and motivation amongst nursing professionals. Linked to, and supporting, this were training, development and progression, which also involved professional nursing care standards, 'evidence-based', best-practice approaches to nursing:

If you are a patient feeling ill, you will want a professional person there all the time doing whatever it is. Whether it is technical skill or whether it's taking them to the loo. They have a better understanding. They have a better knowledge base. They can sense that patient's illness in context of their lives. If they have an unqualified nurse, they are very task orientated, clean cut and dried. They [unqualified nurses] are getting paid less. (Female, age 35, 15 years in NHS, Ward Manager, Oncology, Acute)

Most participants associated NPM with resource management, which they strongly felt curtailed, and often compromised, professional nursing-care standards. Rather than focusing on the quality of care provided, they felt that the 'performance management criteria' emphasised 'cost' as the basis for measuring 'performance'. The participants talked about prioritising and rationing care across the health service, saying that they delivered the best care they could, in the context of a 'resource-constrained' environment:

The reality of it is that we are prioritising, we are rationing indirectly and so therefore the cause which I am committed to is not a reality at the moment. (Female, age 36, 14 years in NHS, Ward Manager, Renal, Acute)

We come under a lot of pressure here. As a nurse I would not be happy to discharge a patient before they are ready, despite management saying we need another body in that bed. (Female, age 40, 22 years in NHS, Staff Nurse, Community) 
The participants viewed the introduction of budgetary principles, more commonly associated with the private sector, as responsible for fewer resources available for quality care, training and development, as well their terms and conditions of employment:

Rather than thinking of patients as individual people you have to treat them like units on a production line. (Female, age 47, 27 years in NHS, Staff Nurse, Renal, Acute)

If you want to get in the league tables you have to push more patients through.

(Male, age 37, 13 years in NHS, Ward Manager, Anaesthetics, Acute)

When I have wasted two hours on a phone fighting for resources that are needed on our ward, I think to myself that was two hours I could have spent on patient care ... Whatever your role is within the NHS your first concern is the patient, or at least it should be.

(Female, age 51, 34 years in NHS, Ward Manager, Community)

They also discussed greater use of unqualified and agency nurses, and fewer resources available for professional training and development, as well as quality patient care.

Due to a lack of trained staff I feel that patients are now been treated as though they were on a conveyer belt. They are in and out. A lot of the care they need requires trained nurses. Obviously no disrespect to untrained staff but trained nurses have been 'trained' to pick up on slight clues and anything they may have not mentioned to the doctor. (Female, age 30, 12 years in NHS, Staff Nurse, Neurology, Acute)

In terms of accommodating managerial identities and discourses some participants were pragmatic. They adopted a flexible approach towards the issue of resource management and managed their own expectations in relation to the resources available for patient care and their own professional training and development. Many, however, talked of 'deskilling', the 'replacement' of qualified with unqualified nurses, and an increased emphasis on 'patient throughput' and work intensification.

It is so difficult to recruit nurses. Now there are more and more unqualified staff. They don't appear to have the same commitment [as fully qualified and trained nurses] for whatever reason whether that be job interest, lack of skills or motivation ... If you take a group of five unqualified nurses and a group of qualified nurses, those unqualified nurses will cost you more over the five years, in levels of sickness, absenteeism and labour turnover. The patient doesn't get the same level of skills, in terms of the person caring for them. (Female, age 35, 15 years in NHS, Ward Manager, Oncology, Acute)

There are nurses leaving and not being replaced. The workforce is decreasing, and the pressures are falling on fewer and fewer people. (Male, age 37, 13 years in NHS, Ward Manager, Anaesthetics, Acute)

The participants also discussed how this impacted on their level of job satisfaction, particularly in relation to the principle of 'direct' and 'holistic' patient care;

Things are missed out. The important things, very often. The basic things are done, the things that make a difference to whether someone lives or dies. But the important things, the little things, like being able to spend time with somebody and talk to them. Listen to their fears and anxieties, being able to sit with a relative who is distressed. That is very often missed out because there is not enough time for it ... This is where nurses are getting their sense of value from ... That is where you get your job satisfaction from. They are being cut out. (Male, age 37, 13 years in NHS, Ward Manager, Anesthetics, Acute)

While the main issue in relation to training and development concerned the resources available, many respondents felt that their current training and development had moved them away from 'bedside care' and had become more 'academic' in nature. They also felt that the new career progression structures were more managerial in nature, which moved them further away from their 'traditional' professional nurse duties, roles and responsibilities: 
I think that people will say to me why haven't you moved on and why don't you take a Ward Sister's post? ... I still like the patient contact. That is what sparks me and keeps me coming back. I would lose that contact if I moved further up. (Female, age 54, 22 years in NHS, Staff Nurse, Community and Rehabilitation)

I find the management side of my post takes over the clinical side. I enjoy the clinical side, but there is more and more management that is being laid at my doorstep. (Female, age 54, 16 years in NHS, Ward Manager, Maternity, Acute)

Participants discussed how senior nursing roles had been redesigned to include greater 'managerial' duties and responsibilities and felt that the promotions available to them were more managerial than professional. They said that they no longer had the freedom of movement or the possibility for promotion within their profession.

\section{Trust}

Addressing the second research question, we now consider how nursing professionals 'talked' about the influence of 'managerialism' on trust between manager-nurse relationships and amongst nursing professionals themselves. We also examine factors that can support or erode trust, and how high trust relationships can be built between nursing professionals and managers.

The participants conceptualised trust in terms of their immediate ward environment, their line-manager and peers - local, as opposed to distant colleagues and managers. Participants discussed 'camaraderie' and 'peer support' amongst their colleagues and manager at ward level as the basis for establishing trust:

There is an element of trust within the smaller environment in which I work. However, within the larger, wider organisational context I think there is a lot of distrust. There is a lot of trust on the ward because of the element of team spirit and also you tend to employ people on the ward who you would naturally warm towards, who have the same ideals on life, and philosophy and so on, and therefore you build up trust, so therefore I think that there is a lot of trust and support. (Female, age 38, 14 years in NHS, Ward Manager, Surgical Ward, Acute)

Nurse-managers at ward level play a significant role in either positively or negatively influencing trust levels both within the ward level and with management outside the ward and the wider organisational environment. The respondents expressed a preference for 'visible', 'hands-on' and 'involved' managers, available for support and guidance.

I think a lot of has to do with how managers, as in me, influence the nurses on the ward. For example, if I go to my line manager, the next level up from me, and I have conflict with them, the way I then come back to the ward and discuss it will either make them [subordinates] trust or mistrust the management or be on their side. It is a lot to do with the way I represent management and if I have a particularly bad deal and am feeling disillusioned with them [management] then I think that would have an impact on the way the rest of the nurses looked at them ... In terms of my feelings about my job, those things are very difficult to hide, because a lot of it comes from body language and individuals can see me when I am particularly stressed. My staff will always support me. (Female, age 36, 14 years in NHS, Ward Manager, Renal, Acute)

I think the higher up you go the less trust there is. Their [management] objectives tend to be different, they tend to be more remote the higher up you get. My immediate manager would be the Ward Sister. I trust her a lot more than I would anyone further up. At the end of the day I am working with her. (Female, age 32, 10 years in NHS, Staff Nurse, Community)

The participants were less trusting of managers outside their immediate ward environment - those they viewed as more 'removed', 'distant' and less understanding of the pressures they were under. Some of the comments suggested frustration with managerial decisions being taken above ward level, by managers with very little understanding of the impact their decisions had at ward level:

I don't think the ground floor employees do [trust management]. Certainly, when I was working three months ago on the wards I wouldn't trust higher level management. Management, from a nurse's point of view, will tell 
you one thing and within ten minutes something else would have happened. They are not honest with their staff, and they need to be. (Female, age 33, 6 years in NHS, Patient Services Manager, Cardiac, Acute)

Staff lower within the organisation were less likely to trust senior management, who were generally viewed as nonnursing. They felt that there was a tendency amongst senior managers to view nurses simply in terms of 'numbers'. They generally considered senior management as 'distant' and 'removed' and did not feel valued by them:

I guess the higher up the ladder you go the more inaccessible you are. Management don't come down to the ward and say hello. Sometimes you desperately need to speak to them. (Female, age 48 years, 27 years in the NHS, Staff Nurse, Community)

Most participants said that high trust levels resulted in positive work environment and patient care outcomes. They described the reciprocal nature of trust, suggesting that it needed to be exchanged between the participants concerned. They said that trust took time to build up and was based on previous experiences. They discussed individuals' willingness to reciprocate as being influenced by several factors, including personality, experience, work history, training, profession and staff association, union membership, political views and psychological contract issues:

I think trust is like respect it has to be built up. It is not automatically given. The only way I can trust anybody is to know them first, that trust has to be built up. I have to know that person and I also have to be in a situation where that trust is actually operational ... Just working and having time to build it up. Perhaps I am a bit cynical I have to build it up in my own steady state. I don't find it easy to trust, but when I do it is solid. (Female, age 48, 28 years in NHS, Staff Nurse, Community)

Participants discussed the influence of previous experiences on the development of trust, and the necessity of 'reciprocating' - 'demonstrating' trust through openness and good communication:

A lot of it is historical [mistrust] and I think that nurses are a professional body which are almost marginalised, because of that they are distrustful as a body, collective and whether or not they ought to be I don't know ... it stems from the fact that they have not being included on things. They do not feel that they have a 'voice'. They feel that issues and different things have been dictated to them. That they have to follow, whereas medical staff and other areas, it's been a question of negotiation. (Female, age 36, 14 years in NHS, Ward Manager, Renal, Acute)

They said that some people were more trusting than others:

As with any manager their agenda might be slightly different to what mine is. So, I would be a bit more reserved about trusting management. (Female, age 32, 10 years in NHS, Staff Nurse, Community)

They suggested that trust both enhanced communication and openness, but also said that mistrust did the opposite.

I think it [mistrust] would hamper communication. I don't think we could operate without having trust for each other ... The benefits are if you trust someone you have an open relationship. There is a whole thing about communication and achieving goals. You wouldn't really be able to operate, I don't think, unless you had trust ... I think achieving goals is about having trust in the manager. (Male, age 37, 13 years in NHS, Ward Manager, Anesthetics, Acute)

Participants felt that some nurses were more proactive in 'constructively engaging' with management. They discussed the importance of feeling that they were 'trusted' by management and given sufficient autonomy to 'get on with' their work in an environment that was free of excessive monitoring and oversight. They felt that proactive engagement, whether or not it was characterised by conflict, communication and reciprocal gestures of goodwill, was linked to the development of trust: 
I wouldn't trust them further than I could throw them. Because of the way they have handled some situations, again some financial situations. They have just handled both situations appallingly. For instance, I am supposed to be here (working on another ward) for a few weeks and then I am supposed to go back to our ward. They keep promising yes you will go back to your ward. Part of me doesn't trust them, part of me says when have you ever seen a hospital ward that is closed down ever opened up again. I haven't! (Female, age 42, 21 years in NHS, Staff Nurse, Community)

There is trust but I think that trust has been eroded to an extent by the uncertainties of the organisation. The Community Trust is undergoing reviews and restructuring, and I think that always has an effect whereby people feel very unsettled, so you start to get mistrust ... The trust from that point of view is not good. As far as day to day running goes there is reasonable trust between the staff ... I think it is historical really [why nurses don't trust managers]. It has always been that way I think it is more so these days because management now, we are led to believe, earn very large salaries. They are very much driven and set tight goals to meet. I know in the past that if they reach these goals there will be a financial incentive for them at the end ... If someone has a personal goal, which is financially driven, they are going to do whatever they can to meet that goal. They are really not going to care how they meet that goal provided they get there. (Female, age 51, 34 years in NHS, Ward Manager, Community)

Poor communication and uncertainty were discussed as factors contributing to mistrust. The participants from the community sector organisation were particularly critical of their management in this regard.

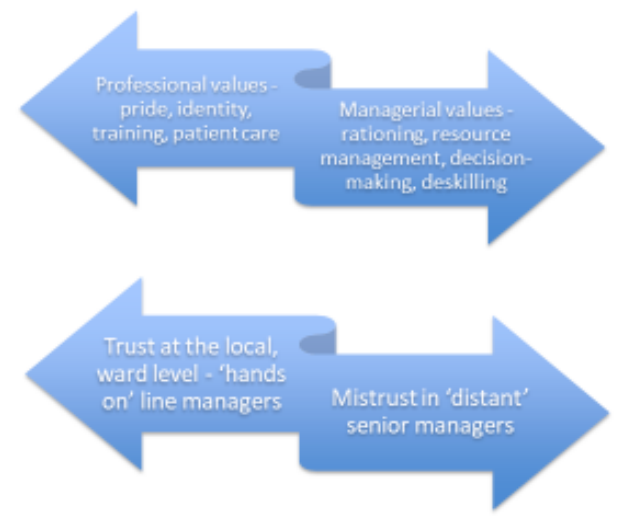

Figure 1. Competing values and conflicting levels of trust

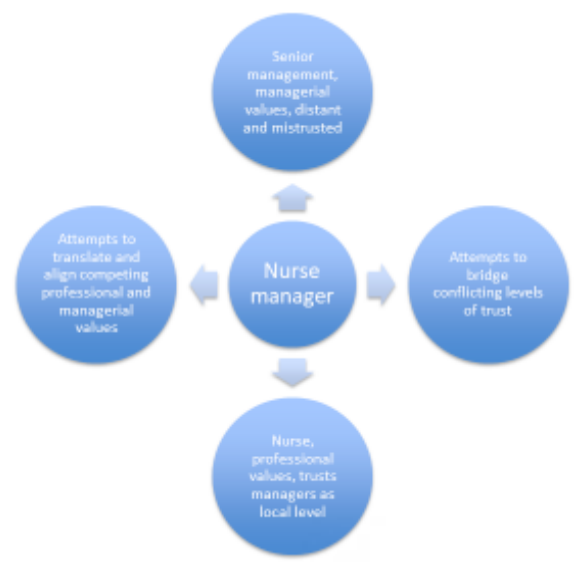

Figure 2. Implications for and central role of nurse manager 


\section{DISCUSSION}

The original data were collected in 2000-2002, at the inception of NPM and managerial discourses in the NHS. Our analysis reveals that nurses and nurse ward managers were already recognising and resisting emerging managerialist practices and associated discourses. The discourse analysis revealed participants' strength of professional identity and commitment to professional values such as competence, autonomy, training, development, 'best practice' nursing and 'holistic' care, as well as the social and humanistic dimension of the nursing role (Carvalho, 2012; O'Donohue and Nelson, 2007).

Some nurses and nurse managers were more flexible towards managerial discourses and values such as 'efficiency', 'resource' and 'performance management' (Nordgren, 2008; Townsend and Wilkinson, 2010). As discussed in the literature, they adopted a flexible approach and expanded their professional boundaries to accommodate new managerial roles and responsibilities (Carvalho, 2012). Many participants deeply resented the implications resource management had for their profession and commitment towards 'best practice', holistic patient care (De Vries and Nemec, 2013). They felt that they were 'prioritising' and 'rationing' health care, in line with the resources available (Cope, 2016). They said that they were managing their expectations and commitment towards their own professional values in relation to patient care, professional development, promotion prospects, their terms and conditions of employment. 'Holistic' care and direct patient contact were viewed as key sources of job satisfaction and motivation for most nursing professionals. They felt that they had been 'lost' through the introduction of NPM discourses, associated practices, systems and processes (Traynor, 1999). Most controversially, resource management was associated with the replacement of trained, qualified nurses with unqualified nursing staff and agency nurses and this was viewed by many as part of a drive to 'deskill' or 'downgrade' the nursing profession. This left many nurses feeling that management did not share their professional values and failed to value their work. They felt that managerial discourses objectified nurses as 'factors of production', referred to patients as 'customers' and 'service users', and availed of healthcare 'products' and 'services'. This was further reflected in talk of 'conveyer belt care' (Beresford and Wallcraft, 1997). Gilbert (2005) also refers to the 'polarisation' of professional and managerial discourses in relation to tensions around costs and care. Furthermore, the literature suggests that nurses in clinical roles struggle with the competing professional and managerial demands of hybrid roles (Croft et al., 2015a), particularly in relation to protecting the caring side of their role (Blomgren, 2003). The discourses highlighted tensions and contradictions in relation to nurse practitioners with managerial roles, responsibilities, and a part in the decision-making. Many nurses feared that greater involvement in decision-making would move them further away from their professional nursing role and direct patient contact. The notion that professional nursing activity has been subject to managerial control is supported by other research (Gilbert, 2005; Traynor, 1999). Many participants felt that professional development and progression were now shaped or 'curtailed' by managerial imperatives and resource management priorities. This was particularly the case when it came to the promotion of nursing staff to senior nurse roles, which had become increasingly 'managerial' in nature (McNamara, 2009). The participants discussed changes to their professional development and progression as becoming increasingly academic and less oriented towards traditional 'frontline', 'bedside care' (Clarke, 2006).

Identity conflict amongst nurses was manifest through anxiety over a loss of professional nursing influence and identity (Croft, et al., 2015b; Fotaki, 2010). Many struggled with their nurse manager leadership roles and responsibilities (Burgess and Currie, 2013). The main challenge for many nurse professionals concerned the need to construct and communicate a leader as well as a collective nursing identity (Martin and Learmonth, 2012; Petriglieri and Stein, 2012). Many encountered difficulties in trying to reconcile competing professional nursing with managerial values and identities (Noordegraaf and De Wit, 2012), ultimately fearing a loss of nursing group influence and professional nursing identity (Croft, et al., 2015b; Fotaki, 2010). Studies have shown that nurses struggled when undertaking professional hybrid roles during a period of identity conflict (Ibarra and Barbulescu 2010) and in balancing their managerial with the professional aspects of their role (Croft et al., 2015b). Studies have also shown that while some nurses embraced managerial discourses (Hallier and Forbes, 2004; Kurunmaki, 2004; Llewellyn, 2001), others 'blended' managerial roles and responsibilities with their professional practice (ledema et al., 2004). Our findings reinforce those of Croft et al. (2015a), that nurses adopt an 'individual-level approach' when balancing professional and managerial responsibilities.

The participants 'talked about' and conceptualised trust primarily in relation to their own immediate ward environment, their direct line manager, and colleagues. The analysis showed that they were more likely to trust those 
who shared their professional nursing values and those working within their immediate work (ward) environment, their colleagues and line manager. Trust was reciprocal in nature and needed to be demonstrated amongst parties. Furthermore, for a number of different reasons, some people were more trusting than others. Trust levels amongst nurses and nurse managers varied according to a number of factors. While some nurses were more inclined to trust management, their attitudes were generally influenced by their previous work experience and history. There was anecdotal evidence to suggest that a history of positive experiences in dealing with management resulted in positive trust outcomes. The analysis also showed that trust could be built and established through open communication and reciprocal gestures demonstrating and showing trust and goodwill. However, new managerialist discourses and associated values, such as resource performance management that oversaw the introduction of unqualified nurses, seemed to work against the development of trust.

Furthermore, it was found that nurse managers played a pivotal role in influencing trust levels at ward level and also in the wider organisation, particularly the manner in which they articulated management decisions, organisational aims and objectives to nurses at ward level. This is supported by other studies (Laschinger and Finegan, 2005; Tallman, 2007). Participants talked of trusting managers whom they considered to be 'hands on' and 'engaged'. They were less inclined to trust managers outside their ward environment, whom they considered to be 'distant and removed' from the work they did.

Confirmed by studies of professional commitment (O'Donohue and Nelson, 2007), our findings suggest the presence of all three elements of Newell and Swan's (2000) concept of trust: companionship, competence, and commitment. However, the introduction of unskilled nurses and new management systems and practices appears to work against one or more of these elements of trust.

\section{CONCLUSION}

We have presented findings from a small qualitative study exploring nurses' and nurse managers' perceptions of managerialism and trust. Although the findings cannot be generalised across other healthcare contexts, nationally and internationally, they offer insight into managerialism and trust amongst nurses and nurse managers within a healthcare context, which globally is becoming more managerialist. Further quantitative research could be undertaken to explore and measure factors associated with managerialism, and its impact on trust within health care organisations.

We argue there are several implications for managers and nurses in healthcare organisations in the British NHS and globally (Figures 1 and 2). First, many nursing professionals viewed managers outside their ward as 'distant' and lacking any insight as to how their decisions impacted at ward level (Brown et al., 2011; Reinders, 2008). Common objectives between management and nursing professionals could perhaps be enhanced if (distant) managers were more aware of the practical consequences their decisions had at the professional-patient interface (Hoyle, 2014).

Second, related to this, some nurses welcomed further involvement in managerial decision-making, which could enhance and help reduce the perceived 'distance' of management. However, other nurses were anxious that this would move them further away from their professional nursing roles and responsibilities. Nurse as opposed to manager identity is strong (Croft et al., 2015; Sambrook 2006) and professional nurse development, along with prominent role models who possess the ability to align and accommodate both identities, might help nurses to 'bridge' this perceived professional-managerial chasm - in what will likely remain managerialist healthcare organisations for the foreseeable future (Reed and O'Reilly, 2011).

Third, perhaps accepting this, some nurses were more positively orientated towards managerial roles and responsibilities and adopted a practical approach towards managerial discourses, such as resource and performance management (Carvalho, 2012; Hallier and Forbes, 2004; Llewellyn, 2001; Kurunmaki, 2004). These (local) nurse ward managers could play an important role in liaising between management and ward-level staff, 'translating' managerialist discursive resources into more 'nurse-friendly' terms. Our findings demonstrate that many nurses resented resource and performance management for curtailing patient care and their professional obligations (Blomgren, 2003), a practice which also left many nurses feeling devalued. Yet, nurse managers have an important but difficult role in responding to managerialist imperatives, while attempting to secure commitment from their professional nursing staff (Gilbert, 2005; Tallman, 2007).

Fourth, nurses tended to view trust as more significant at ward level, amongst their peers and nurse managers, and were less likely to trust management outside their ward environment. The pivotal role of nurse managers' 
leadership skills in increasing or decreasing trust in middle and senior-level management was highlighted by nurses and nurse managers (Laschinger and Finegan, 2005; Calnan and Rowe, 2006). Nurse ward managers should be fully supported in this fragile yet crucial bridging position.

To conclude, our findings suggest tensions between professional nursing and managerial priorities and discourses surrounding healthcare delivery. It appears that the introduction and advancement of managerialist discourses eroded trust in management, at a time when ongoing changes and increasing challenges required professional commitment - a key aspect of trust. Nurse ward managers play a crucial bridging role in tempering and translating managerialism to sustain nurses' trust to deliver professional health care.

\section{References}

Allen, D. (2004), 'Re-reading nursing and rewriting practice: Towards an empirically based reformulation of the nursing mandate'. Nursing Inquiry 11: 4, 271-283.

Bennis, W., \& Nanus, B. (1985). Leaders: The strategies for taking charge. New York: Harper \& Row.

Bejerot, E. and Hasselbladh, H. (2011). 'Professional autonomy and pastoral power: The transformation of quality registers in Swedish healthcare'. Public Administration 89: 4, 1604-1621.

Beresford P, Wallcraft J (1997). Psychiatric system survivors and emancipatory research: issues, overlaps and differences. In: Barnes C, Mercer G. Doing disability research. . Leeds, Disability Press.

Blomgren, M. (2003). 'Ordering a profession: Swedish nurses encounter new public management reforms'. Financial Accountability \& Management, 19, 45-71.

Bresnen, M., Hodgson, D., Bailey, S., Hyde, P. and Hassard, J. (2017). 'Mobilizing management knowledge in healthcare: Institutional imperatives and professional and organizational mediating effects'. Management Learning, 48:5, 597-614.

Brown P., Alaszewski A., Pilgrim D. and Calnan M. (2011). 'The quality of interaction between managers and clinicians: A question of trust'. Public Money and Management 31:1, 43-50.

Buchan, J., May, F. and Dussault, G. (2013). 'Nursing workforce policy and the economic crisis: A global overview'. Journal of Nursing Scholarship, 45: 3 , 298-307.

Burgess, N. and Currie, G. (2013). 'The knowledge brokering role of the hybrid middle level manager: The case of healthcare'. British Journal of Management, 24, S132-S142.

Calnan, M. and Gabe J. (2001). 'From consumerism to partnership?' Britain's National Health Services, 31: 1, 119-131.

Calnan, M. and Rowe, R. (2006). 'Researching trust relations in health care: Conceptual and methodological challenges - an introduction.'
Journal of Health Organisation and Management, 20: 5, 349-358.

Carter, B. (2007). 'Review: symposium on managing to nurse: Inside Canada's health care reform. Reformatting nursing: The invidious effects of the growth of managerialism.' Health, 11: 2, 268-272.

Carvalho, T. (2012). 'Managerialism and professional strategies: A case from nurses in Portugal'. Journal of Health Organization and Management, 26: 4, 524-541.

Clarke, S. (2006). 'Research on nurse staffing and its outcomes: The challenges and risks of grasping at shadows', in S. Nelso and S. Gordon (eds), The Complexities of Care, New York: Cornell University Press.

Connell, N.A.D. and Mannion, R. (2006). 'Conceptualisations of trust in the organisational literature'. Journal of Health Organization and Management, 20: 5, 417-433.

Cope, V., Jones, B. and Hendricks, J. (2016). 'Resilience as resistance to the new managerialism: Portraits that reframe nursing through quotes from the field.' Journal of Nursing Management, 24:1, 115-122.

Croft, C., Currie, G. and Lockett, A. (2015a). 'Broken "two-way windows"? An exploration of professional hybrids.' Public Administration, 93: 2, 380-394.

Croft, C., Currie G. and Lockett, A. (2015b). 'The impact of emotionally important social identities on the construction of a managerial leader identity: A challenge for nurses in the English National Health Service, Organization Studies, 36:1, 113-131.

Crowe, M. (2005). 'Methodological issues in nursing research, Discourse analysis: towards an understanding of its place in nursing'. Journal of Advanced Nursing, 51:1, 55-63.

Currie, G. and Lockett, A. (2007). 'A critique of transformational leadership: Moral, professional and contingent dimensions of leadership within public services organizations. Human Relations, 60, 341-370.

De Vries, M. and Nemec, J. (2013). 'Public sector reform: 
An overview of recent literature and research on NMP and alternative paths'. International Journal of Public Sector Management 20:1, 4-16.

Fairclough N. and Wodak, R. (1997). 'Critical discourse analysis: An overview', in T. Van Dijk (ed.), Discourse and Interaction, London: Sage.

Felstead, A., Gallie, D., Green, F. and Inanc, H, (2013). Work Intensification in Britain: First Findings from the Skills and Employment Survey 2012. London: Institute of Education.

Ferlie, E., Fitzgerald, L., McGivern, G., Dopson, S. and Bennett, C. (2013), Making Wicked Problems Governable: The Case of Managed Networks in Health Care. Oxford: Oxford University Press.

Fotaki, M. (2010). 'Why do public policies fail so often? Exploring health policy-making as an imaginary and symbolic construction'. Organization, 17, 703720.

Freidson, E. (2001), Professionalism: The Third Logic, Cambridge: Polity Press.

Gilbert, T.P. (2005), "Trust and managerialism: exploring discourses of care", Journal of Advanced Nursing, 52 (4) 454-63.

Gilson, L. (2003). 'Trust and the development of health care as a social institution'. Social Science and Medicine, 56, 1453-68.

Gilson L., (2006). 'Trust in health care: Theoretical perspectives and research needs'. Journal of Health Organization and Management, 20: 5, 359375.

Granter, E., Wankhade, P., Mccann, L., Hyde, P. and Hassard, J. (2018). 'Multiple dimensions of work intensity: Ambulance work as edgework'. Work, Employment \& Society. First published online: 19 March, 2018. http://journals.sagepub.com/doi/abs /10.1177/0950017018759207?journalCode=wesa [Accessed 03 November 2018].

Hallier, J. and Forbes, T. (2004). 'In search of theory development in grounded investigations: Doctors' experiences of managing as an example of fitted and prospective theorizing'. Journal of Management Studies, 41: 8, 1379-410.

Hassard, J., Hyde, P., Cox, W.J., Granter, E. and McCann, L. (2017). 'Exploring health work: A critical-action perspective'. Journal of Health Organization and Management, 31: 5, 567-580.

Hoyle L. (2014). 'Nurses' perception of senior managers at the front line: People working with clipboards'. Journal of Advanced Nursing 70: 11, 2528-2538.

Hunter, D.J. (2007). 'Exploring managing for health', in D.J. Hunter (ed.), Managing for Health, Abingdon: Routledge.

Hyde, P., Granter, E., Hassard, J. and McCann,
L. (2016), Deconstructing the Welfare State, London:Routledge.

Ibarra, H. and Barbulescu, R. (2010). 'Identity as narrative: Prevalence, effectiveness, and consequences of narrative identity work in macro role transitions'. Academy of Management Review, 35: 1, 135-54.

ledema, R., Degeling, P., Braithwaite, J. and White, L. (2004). 'It's an interesting conversation I'm hearing': The doctor as manager. Organization Studies 25:1, 15-33.

Jefferson, T., Klass, D., Lord, L., Nowak, M. and Thomas, G. (2014). 'Context and the leadership experiences and perceptions of professionals'. Journal of Health Organization and Management, 28: 6, 811-829.

Kurunmaki, L. (2004). 'A hybrid profession: The acquisition of management accounting expertise by medical professionals. Accounting Organizations and Society, 29:3/4, 327-347.

Kvale, S. (1996), Interviews: An Introduction to Qualitative Research Interviewing, London: Sage.

Laschinger, H.K.S. and Finegan, J. (2005). 'Using empowerment to build trust and respect in the workplace: A strategy for addressing the nursing shortage'. Nursing Economics, January-February, 23: $1,6-13$.

Latimer, J. (2000), The Conduct of Care: Understanding Nursing Practice, Oxford: Blackwell Science.

Learmonth, M. (2017). 'Making history critical: Recasting a history of the "management" of the British National Health Service'. Journal of Health Organization and Management, 31: 5, 542-555.

Llewellyn, S. (2001), "'Two-way windows": Clinicians as medical managers'. Organization Studies, 22:4, 593-623.

MacDonald, K. (1995), The Sociology of the Professions, Sage, London.

Marinetto, M. (2011). 'A Lipskian analysis of child protection failures from Victoria Climbie to "Baby P": A street-level re-evaluation of joined-up governance'. Public Administration, 89: 3, 1164-81.

Martin, G. P. and Learmonth, M. (2012). 'A critical account of the rise and spread of "leadership": The case of UK healthcare'. Social Science \& Medicine 74: 3, 281-288.

McCabe, T.J. and Garavan, T.N. (2008). 'A study of the drivers of commitment amongst nurses, the salience of training and development and career issues'. Journal of European Industrial Training, 32: 7, 528-568.

McNamara, M. (2009). 'Nursing academics' languages of legitimation: A discourse analysis'. International Journal of Nursing Studies, 46, 1566-1579. 
Newell, S. and Swan, J. (2000). 'Trust and interorganizational networking'. Human Relations, 53: 10, 1287-1328.

Newman, K., Maylor, U. and Chansarkar, B. (2002). 'The nurse satisfaction, service quality and nurse retention chain: Implications for management of recruitment and retention'. Journal of Management in Medicine, 16: 4, 271-291.

Nordgren, L. (2008). 'The performity of the service management discourse: "Value creating customers" in health care'. Journal of Health Organisation and Management, 22: 5, 510-528.

Noordegraaf, M. and De Wit, B.A.S. (2012). 'Responses to managerialism: How management pressures affect managerial relations and loyalties in education'. Public Administration, 90, 957-973.

O'Donohue, W. and Nelson, L. (2007). 'Let's be professional about this: Ideology and the psychological contracts of registered nurses'. Journal of Nursing Management, 15, 547-555.

O'Reilly, D. and Reed, M. (2010), “Leaderism": An evolution of managerialism in UK public service reform'. Public Administration, 88: 4, 960-978.

Peter, E. and Morgan, K.P. (2001). 'Explorations of a trust approach for nursing ethics'. Nursing Inquiry, 8: 1, 3-10.

Petriglieri, G. and Stein, M. (2012). 'The unwanted self: Projective identification in leaders' identity work'. Organization Studies, 33, 1217-1235.

Potter, J. and Wetherell, M. (1987). Discourse and Social Psychology: Beyond Attitudes and Behaviour, London: Sage.

Pratt, M.G., Rockmann, K.W. and Kaufmann, J.B. (2006). 'Constructing professional identity: The role of work and identity learning cycles in the customization of identity among medical residents'. Academy of Management Journal, 49: 2, 235-62.

Reed, M. (2002). 'New managerialism, professional power and organisational governance in UK universities: A review and assessment', in A. Amaral, G. Jones and B. Karseth (eds), Governing Higher Education: National Perspectives on Institutional Governance, Dordrecht: Kluwer University Publishers.

Reed, M. and O'Reilly, D. (2011). 'The grit in the oyster: Professionalism, managerialism and leaderism as discourses of UK public services modernization'. Organization Studies, 32: 8, 1079-1101.

Reinders, H. (2008). 'The transformation of human services'. Journal of Intellectual Disability Research, 52: 7, 564-572.

Rowe, R. and Calnan, M. (2006). 'Trust relations in health care: Developing a theoretical framework for the "new" NHS'. Journal of Health Organization and Management, 20: 5, 376-396.

Rydenfält C., Johansson G., Larsson P.A., Akerman K. and Odenrick P. (2012). 'Social structures in the operating theatre: How contradicting rationalities and trust affect work'. Journal of Advanced Nursing, 68: 4, 783-795.

Sambrook, S. (2000). 'Talking of HRD'. Human Resource Development International, 3: 2, 159-78.

Sambrook, S. (2001). 'HRD as an emergent and negotiated evolution: An ethnographic case study in the British National Health Service'. Human Resource Development Quarterly, 12: 2, 169-193.

Sambrook, S. (2006). 'Management development in the NHS: Nurses and managers, discourses and identities'. Journal of European Industrial Training, 30: 1, 48-64.

Scudder, L.E., Rheaume, A., Clement, L. and LeBel, N. (2011). Why new graduate nurses quit their first jobs'. International Journal of Nursing Studies, 48, 490-500.

Skinner, D., Saunders, M. and Duckett, H. (2004). 'Policies, promises and trust: Improving working lives in the National Health Service'. International Journal of Public Sector Management, 17: 7, 558570.

Smircich, L., \& Morgan, G. (1982). Leadership: The Management of Meaning. The Journal of Applied Behavioral Science, 18, 257-273.

Stewart, J. and Sambrook S. (2007). 'HRD in health and social care: The emerging challenges', in $\mathrm{S}$. Sambrook and J. Stewart (eds), Human Resource Development in the Public Sector, London: Routledge.

Tallman, R. (2007). 'Does trust matter?: Perceptions, trust and job satisfaction of hospital nurses'. International Journal of Business Research, 7: 4, 200-211.

Townsend, K. and Wilkinson, A. (2010). 'Managing under pressure: HRM in hospitals'. Human Resource Management Journal, 20: 4, 332-338.

Traynor M. (1999). 'Managerialism and Nursing: Beyond Profession and Pppression, London: Routledge.

Tummers, L., Bekkers, V. and Steijn, B. (2009). 'Policy alienation of public professionals: Application in a new public management context'. Public Management Review, 11: 5, 685-706.

Tummers, L., Steijn, B. and Bekkers, V. (2012). 'Explaining the willingness of public professionals to implement public policies: Content, context, and personality characteristics'. Public Administration, 90: 3, 716-736.

Wallace, M. and Pocklington, K. (2002). Managing 
Complex Educational Change: Large Scale Reorganisation of Schools, London: Routledge Falmer.

Williams, L.L. (2005). 'Impact of nurses' job satisfaction on organisational trust'. Health Care Management Review, 30; 3, 203-211.
Yu, K.H. and Levy, F. (2010). 'Offshoring professional services: Institutions and professional control'. British Journal of Industrial Relations 48: 4, 758783. 